EPISTEME KOINONIA

Revista Electrónica de Ciencias de la Educación, Humanidades, Artes y Bellas Artes

Año III. Vol III. N ${ }^{\circ}$. Enero - Junio, 2020

Hecho el depósito de Ley: FA2018000022

ISSN: 2665-0282

FUNDACIÓN KOINONIA (F.K)

Santa Ana de Coro, Venezuela

Florihza González

http://dx.doi.org/10.35381/e.k.v3i5.528

\title{
La gerencia del aula desde la vocación del colectivo docente
}

\section{Classroom management from the vocation of the teaching collective}

\author{
Florihza González \\ florihza@gmail.com \\ Centro de Educación Inicial Bolivariano Lucrecia de Guardia, Santa Ana de Coro. \\ Venezuela \\ https://orcid.org/0000-0002-0644-5778
}

Recepción: 15 Julio 2019

Revisado: 31 Julio 2019

Aprobación: 23 Agosto 2019

Publicación: 01 Enero 2020

\section{RESUMEN}

La investigación tuvo por objetivo analizar la gerencia del aula desde la vocación del colectivo docente de la CEIB Lucrecia de Guardia, ubicada en Coro, municipio Miranda del Estado Falcón - Venezuela, fue de carácter descriptivo con una población de 18 docentes a quienes se les aplicó un instrumento tipo Likert de 13 alternativas de respuestas. Los aspectos que definen la vocación del docente de educación inicial van enfocados hacia la capacidad de trabajar en equipo, responsabilidad, tareas manuales, salud física y mental, buen trato entre colegas, tolerancia, paciencia, firmeza, cualidades morales; elementos que se evidencian en cada uno de los docentes que conforma dicho colectivo. El compromiso y la responsabilidad juegan un papel importante en los años de servicio ejerciendo la docencia, más colectivo que individual pero implica una cohesión social que permite como organización educativa social tener una proyección positiva ante la comunidad.

Palabras clave: Responsabilidad del docente; papel del docente; calidad de la educación; pertinencia de la educación. (Palabras tomadas del Tesauro UNESCO).

\section{ABSTRACT}

The objective of the research was to analyze the management of the classroom from the vocation of the teaching collective at Lucrecia de Guardia Early Childhood Education Center, located in Coro, Miranda municipality, Falcon State- Venezuela. The study was descriptive in nature with a population of 18 teachers to whom a Likert-type instrument with 13 response alternatives was applied. The aspects that define teacher's vocation at 




initial education are focused on the ability to work in teams, responsibility, manual tasks, physical and mental health, good treatment among colleagues, tolerance, patience, firmness and moral qualities; elements that are evident in each of the teachers that integrate this group. Commitment and responsibility play more important collective than individual roles in the years of service by teaching, but it implies a social cohesion that allows social educational organization to have a positive projection in the community.

Keywords: Teacher's responsibility; teacher's role; educational quality; educational relevance. (Words taken from UNESCO Thesaurus).

\section{INTRODUCCIÓN}

Desde la globalización y complejidad que caracteriza la actualidad, existe un punto crucial desde los escenarios educativos que permite establecer lo afectado que se encuentra la labor docente, al hacer referencia al proceso escolar cada autor le otorga significado a aspectos particulares, algunos se inclinan hacia el currículo, otros la estructura física, unos la gerencia, otros hacia el ser humano que está formado académicamente para ejercer el rol del docente, un rol que en tiempos de crisis, especialmente debe ser estudiado, considerando que no es una labor sencilla.

Actualmente, la era de la complejidad, influye en todos los ambientes sociales, sin excluir al educativo, sus protagonistas en escenarios micros como un aula de clases, ante esta realidad el docente debe promover ideas y requerimientos novedosos, creativos, innovadores para que su accionar pedagógico no se pierda en tanta incertidumbre. Él debe propiciar opciones y alternativas para lograr aprendizajes significativos y un proceso de enseñanza aprendizaje que los forme para la vida, más allá de los procesos cognitivos. Cabe destacar que el ser docente de vocación implica no solo un compromiso con el cual dirige su aula, sino además contar con elementos importantes para hacer de su práctica pedagógica un encuentro placentero y gratificante para él, su grupo de niños y familias, e incluso los colegas; estos aspectos no se pueden desligar del deber ser de la profesión docente, sobre todo cuando se hace referencia a la educación inicial, elementos como motivación, capacidades, aptitudes, habilidades, destrezas y creatividad tiene que formar 


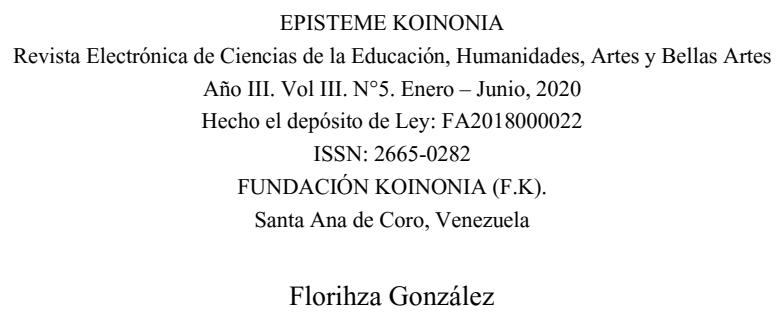

parte del accionar pedagógico generando una labor significativa desde los contextos de aula, familiares y comunitarios.

La importancia de un docente que esté formado bajo la integridad de estos aspectos se encuentra en la capacidad de hacer frente de forma asertiva a las incertidumbres y episodios repentinos que se generan en las aulas, por cuanto repercuten en la labor gerencial que se propone. Romero \& Villasmil (2017).

Por lo tanto, el docente contribuye a la formación de las personas de acuerdo a los intereses y requerimientos de la sociedad, permite que crezcan como seres humanos, profesionales, laboriosos, ciudadanos, dejar a un lado las particularidades e individualidades para convertirse en un ser social con otros. A lo que Lapati (2003) refiere que:

Ser maestro hoy tiene afortunadamente otros rasgos que se inscriben en su lado luminoso y se descubren cuando logramos trascender las pequeñas miserias de la cotidianidad y recuperar lo esencial, lo que alguna vez nos atrajo como "vocación": el amor a los niños y a los jóvenes, el deseo de ayudarles, de abrir sus inteligencias, de acompañarlos en su proceso para llegar a ser hombres y mujeres de bien (p. 23).

En este sentido, el compromiso de los docentes es hacer de la labor pedagógica un acto de vocación, la misma que le permite generar metas, desafíos y grandes obras para los estudiantes, un docente sin vocación pudiera ser un profesional viciado, rutinario, falto de creatividad, sentido, pertenencia y entusiasmo.

La vocación es un término que ha sido descrito por varios autores, para Pérez (2004): "la palabra tiene un origen religioso: en latín, vocare significa "llamar". En su acepción original, la vocación es un llamado de Dios. Hay profesiones que son más "vocacionales" que otras; la docencia es una de ellas" (p. 12). Sin embargo, la tarea docente requiere de cualidades personales innatas que fortalezcan la profesión.

En este sentido, la vocación docente va más allá de la simple praxis de la pedagogía del maestro, es sus emociones, misión y visión, proyección de vida, relaciones interpersonales, la conformidad positiva con su trabajo, sus estudios, investigaciones, 


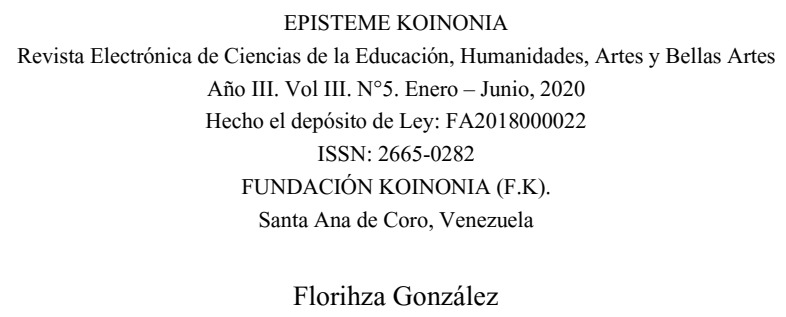

inteligencia emocional; son muchas partes, muchos elementos que conforman la personalidad del docente, y que esta forma parte necesaria dentro de lo que es su pedagogía.

Como docentes se debe ubicar la vocación en el contexto donde se desarrolla la labor pedagógica, una labor que debe salir de las cuatro paredes de un aula, que debe permitirse ser flexibles ante los currículos llenos de objetivos preestablecidos, que observe en cada estudiante parte de sus hijos... de su corazón de madre o padre, ser capaces de ser amigo de sus estudiantes, y de su familia, ser parte fundamental del proceso formativo de ese niño, a quien se nos entrega para hacerlo alguien de bien.

Es en función de esta concepción, que el docente desde su verdadera e inquietante vocación convierta sus espacios de aprendizaje, dentro o fuera del aula, como espacios vitales gerenciales, pues desde su accionar pedagógico se deben generar experiencias y construcción de aprendizajes cónsonos con la realidad y con los intereses y potencialidades de los niños. Por esta razón, se habla del docente como un gerente, un mediador de procesos: planificación, evaluación, liderazgo, organización; una serie de aspectos teóricos prácticos que debe llevar a cabo el docente desde su labor, y que es enriquecida desde su vocación profesional, Borrero (2019).

En este sentido, Ruiz (1992), plantea que "la gerencia de aula se refiere a la previsión y procedimientos necesarios para establecer y mantener un ambiente en el cual la instrucción y el aprendizaje puedan suceder" (p. 8). Por lo tanto, el aula y los espacios de aprendizaje desde la educación inicial son importantes porque el docente es quien los dirige y gerencia en función del beneficio de niños, niñas y padres. Solo a través del sentido vocacional el docente es innovador, proactivo, ingenioso, critico, reflexivo, creativo para garantizar desde sus espacios procesos de enseñanza aprendizaje ideales y significativos, asumir un rol gerencial desde los espacios micros de una institución educativa es concentrar los esfuerzos y funciones en la búsqueda de la calidad educativa y la excelencia académica, Hernández (2018). 


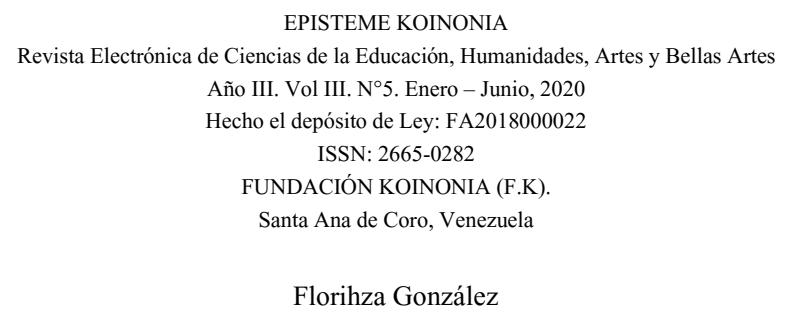

Según Méndez (2004), la idea de excelencia, debe ser entendida, como "el propósito de esforzarse en ser cada día mejor, para no contentarse con lo fácil, sino en trazarse metas exigentes que lo conviertan en un ser apto y socialmente realizado que es lo que persigue una educación integral" (p. 13). La función docente dejo de ser una mera trasmisión de conocimientos, evaluar y dar instrucciones, se dirige hacia incentivar y motivar a niños, niñas y sus familias para el logro de procesos de aprendizajes integrales y cónsonos para una formación acorde a las exigencias sociales, todo ello enmarcado en una gerencia y liderazgo docente, para Salazar (1994), el docente gerente de aula tiene: "la capacidad de articular, conceptualizar, crear y promover espacios y posibilidades para un cambio crítico y efectivo de las condiciones que inhiben el mejoramiento de todos y para todos" (p. 3).

Se consolida como un profesional que gestiona soluciones, convierte las complejidades e incertidumbres en fortalezas, un visionario sobre lo que su grupo de niños debe aprender, investigador, de actitud humilde, un docente preocupado y ocupado en las necesidades de su aula y su grupo, participativo, respetuoso, con actitud positiva hacia la escucha y el intercambio. Desde la concepción del docente como gerente de aula con una sólida vocación de servicio se traduce una praxis pedagógica con amor y preparación para que el acto de enseñar sea dinámico, transformante, crítico y efectivo, buscando la formación de niños, niños y sus familias, desarrollando personalidades integras y seres humanos autónomos.

Según Dubet, Duru y Bellat (2000), "existe siempre una distancia entre la imagen ideal que los docentes se hacen de su vocación y de su función, y la realidad de su práctica, a menudo decepcionante, dado el estado delos alumnos y de la sociedad" (p. 19), es decir, estos autores consideran que existen incongruencias sobre el sentido vocacional que tiene el docente hacia una praxis pedagógica de excelencia así como las condiciones de la realidad donde esta se ejerce. Estas debilidades afectan en cierta medida la vocación que tenga el docente, dificultando una gerencia de aula no cónsona con sus ideales y metas profesionales, así como los requerimientos de los niños, niñas y familia. 


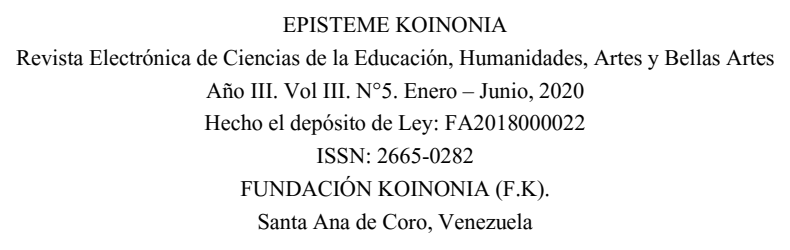

Florihza González

En este sentido, la realidad observada y en conversaciones con acompañante pedagógico y el resto de los docentes, desde el contexto laboral del CEIB Lucrecia de Guardia, hace referencia a un grupo de docentes que no van más allá de lo plasmado a través de los lineamientos, utilizando una pedagogía tradicional, la cual mutila pedagógicamente al grupo de niños. No se evidencian estrategias innovadoras, creativas; incluso la propia apariencia de algunos docentes no motiva a los niños a iniciar con entusiasmo su jornada diaria; el trato hacia los niños en ocasiones es producto de la falta de vocación.

Dentro de este orden de ideas, se observa un desinterés y desmotivación hacia el cumplimiento de las funciones y tareas propias de cada docente, se evidencian preocupaciones de los docentes de otro índole fuera del contexto laboral y escolar como: falta de alimentos, carencia económica, problemas con el transporte, horario del suministro de agua; todos estos problemas que son perjudiciales para el desempeño docente desde una vocación efectiva.

Asimismo, la presentación y ejecución de planificaciones monótonas con el grupo de niños, poco contacto con los padres y representantes, encierro dentro de sus aulas sin otras opciones para el desarrollo de la acción pedagógica, poca iniciativa en realizar actividades significativas, toma de decisiones no efectivas hacia las preocupaciones y debilidades de aula y los procesos pedagógicos. Estas acciones definen a un docente sin vocación y liderazgo desde su práctica profesional, donde no hay incentivo para romper paradigmas y abandonar las rutinas, hábitos que impiden una pedagogía más innovadora y creativa. Es así que la investigación tuvo por objetivo analizar la gerencia del aula desde la vocación del colectivo docente de la CEIB Lucrecia de Guardia, ubicada en Coro, municipio Miranda del Estado Falcón - Venezuela.

\section{METODOLOGÍA DE LA INVESTIGACIÓN}

La investigación fue de tipo descriptiva, en este sentido, la investigación permitió describir la gerencia del aula desde la vocación del colectivo docente del Centro de Educación 


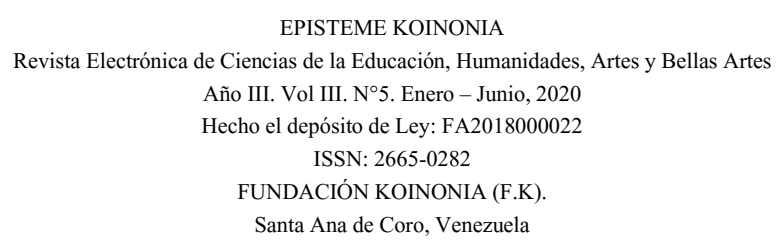

Florihza González

Inicial Bolivariano Lucrecia de Guardia. Este tipo de investigación además de tabular datos, interpreta, describe y mide; con el propósito de realizar una evaluación de la información que se obtiene, para lo cual se prosiguió con lo planteado por Arias (2009). Los datos fueron obtenidos a través de la experiencia empírica, se llaman primarios cuando son datos de primera mano, al contrario cuando han sido recolectados con anterioridad se denominan secundarios, recolectados por otros. Para el caso de esta investigación, los datos fueron recopilados de la muestra del Centro de Educación Inicial Bolivariano Lucrecia de Guardia. La población estuvo constituida por dieciocho docentes (18) que laboran en el CEIB Lucrecia de Guardia, se empleó la encuesta y se aplicó un instrumento de 13 preguntas cerradas con alternativas: siempre, casi siempre, algunas veces, casi nunca y nunca; a fin de medir la variable de la investigación, el cual tuvo un coeficiente de Alfa de Cronbach de 0,98 catalogándose como altamente confiable para su aplicación.

\section{RESULTADOS}

En este apartado, contentivo de la presentación y análisis de los resultados implica el tratamiento de los datos obtenidos en el contacto con la realidad estudiada a través del cuestionario el cual fue diseñado por la autora y estuvo dirigido a docentes (18) que laboran en el CEIB Lucrecia de Guardia. Consta de 13 preguntas con una escala de estimación, con las alternativas siempre, casi siempre, algunas veces, casi nunca y nunca. 
EPISTEME KOINONIA

Revista Electrónica de Ciencias de la Educación, Humanidades, Artes y Bellas Artes

Año III. Vol III. N ${ }^{\circ}$. Enero - Junio, 2020

Hecho el depósito de Ley: FA2018000022

ISSN: 2665-0282

FUNDACIÓN KOINONIA (F.K)

Santa Ana de Coro, Venezuela

Florihza González

Cuadro 1

Respuestas del Ítem 1 Posee atracción hacia su profesión

\begin{tabular}{lll} 
Opciones & Frecuencia & Porcentaje \\
\hline Siempre & 4 & $22 \%$ \\
Casi siempre & 12 & $67 \%$ \\
Algunas veces & 2 & $11 \%$ \\
Casi nunca & - & \\
Nunca & - & \\
Total & 18 & $100 \%$ \\
\hline
\end{tabular}

Los docentes encuestados manifestaron en un $67 \%$ que casi siempre poseen atracción hacia su profesión, seguido con una diferencia marcada un $22 \%$ con la opción algunas veces, y con un $11 \%$ la opción siempre. Estos resultado permiten tomar en consideración que la atracción hacia la carrera docente, especialmente en el nivel de educación inicial si es posible, en comparación con aquellos docentes que han tomado esta profesión por simple capricho o por considerarla "lo más fácil". Desde esta perspectiva, se toma en consideración lo aportado por Sánchez (2003) quien refiere que esta atracción es considerada desde la vocación subjetiva como aquella donde se siente atracción por la actividad pero no posee las cualidades necesarias para ejercerla.

Cuadro 2

Respuestas del Ítem 2 Tiene las cualidades para su profesión

\begin{tabular}{|c|c|c|}
\hline Opciones & Frecuencia & Porcentaje \\
\hline Siempre & 4 & $22 \%$ \\
\hline Casi siempre & 1 & $5 \%$ \\
\hline Algunas veces & 10 & $56 \%$ \\
\hline Casi nunca & 3 & $17 \%$ \\
\hline Nunca & - & - \\
\hline Total & 18 & $100 \%$ \\
\hline
\end{tabular}




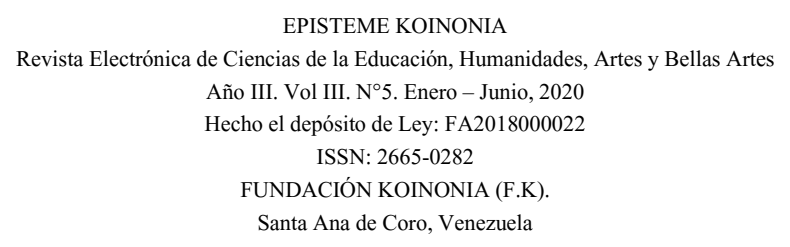

Florihza González

El grupo de docentes encuestados manifestaron con respecto a las cualidades que poseen para su profesión que el $56 \%$ algunas veces sobresalen, seguido de un $22 \%$ con siempre, un $17 \%$ con la opción casi nunca y un $5 \%$ casi siempre. Las cualidades para ser docente de educación inicial deben ser una condición importante para desempeñarse en este nivel, pues el trabajo es con niños más pequeños, en comparación con otros niveles implica paciencia, amor, comprensión, además de dominio en habilidades manuales y un alto grado de innovación y creatividad. Por su parte, Sánchez (2003) considera que la vocación de este tipo se denomina objetiva, es decir, tiene las cualidades para llevarla a cabo, pero no se siente atraído por ella.

Cuadro 3

Respuestas del Ítem 3 Tiene vocación docente autentica

\begin{tabular}{lll} 
Opciones & Frecuencia & Porcentaje \\
\hline Siempre & 4 & $22 \%$ \\
Casi siempre & 2 & $11 \%$ \\
Algunas veces & 12 & $67 \%$ \\
Casi nunca & - & \\
Nunca & - & \\
Total & 18 & $100 \%$ \\
\hline
\end{tabular}

El $67 \%$ de los encuestados manifestaron que algunas veces tienen vocación docente autentica, seguido de una marcada diferencia con la opción siempre en un $22 \%$, y por ultimo un $11 \%$ con la opción casi siempre. La vocación docente autentica es aquella que se observa bajo parámetros armónicos entre docente- niños- padres y representantes, implica un desempeño pedagógico fascinante, para Sánchez (2003) este tipo de vocación se denomina vocación autentica por que el profesional tiene la atracción y las cualidades para ello. 
EPISTEME KOINONIA

Revista Electrónica de Ciencias de la Educación, Humanidades, Artes y Bellas Artes

Año III. Vol III. N ${ }^{\circ}$ 5. Enero - Junio, 2020

Hecho el depósito de Ley: FA2018000022

ISSN: 2665-0282

FUNDACIÓN KOINONIA (F.K)

Santa Ana de Coro, Venezuela

Florihza González

Cuadro 4

Respuestas del Ítem 4 Su accionar pedagógico lo mantiene motivado

\begin{tabular}{lll} 
Opciones & Frecuencia & Porcentaje \\
\hline Siempre & 4 & $22 \%$ \\
Casi siempre & 3 & $17 \%$ \\
Algunas veces & 11 & $61 \%$ \\
Casi nunca & - & - \\
Nunca & - & - \\
Total & 18 & $100 \%$ \\
\hline
\end{tabular}

El $61 \%$ de los docentes encuestados considera que algunas veces su accionar pedagógico lo mantiene motivado, seguido de un $22 \%$ que opinan con la opción siempre y un $17 \%$ con la opción casi siempre. Esta información permite afirmar que la motivación es un factor importante en el desempeño pedagógico del docente, cuando decae este nivel se ve afectado su desenvolvimiento, incluyendo la acción directa con los niños. La motivación del docente, para Robbins (1999) la motivación es: "la voluntad de ejercer altos niveles de esfuerzo hacia el logro de las metas, sea estas personales $u$ organizacionales" (p. 168).

Cuadro 5

Respuestas del Ítem 5 Desde su práctica pedagógica ha desarrollado capacidades con el tiempo

\begin{tabular}{lll} 
Opciones & Frecuencia & Porcentaje \\
\hline Siempre & 6 & $33 \%$ \\
Casi siempre & 8 & $45 \%$ \\
Algunas veces & 4 & $22 \%$ \\
Casi nunca & - & - \\
Nunca & - & - \\
Total & 18 & $100 \%$ \\
\hline
\end{tabular}






Florihza González

Los encuestados consideran en un $45 \%$ que casi siempre su práctica pedagógica ha desarrollado capacidades con el tiempo, seguido de la opción siempre con un 33\% y un $22 \%$ algunas veces. La experiencia y los años de servicio acumulan muchos elementos que fortalecen la profesión, los docentes del CEIB Lucrecia de Guardia manifiestan se han desarrollado con mayor y mejor actitud hacia su profesión a medida que transcurre el tiempo. En tal sentido, Jiménez (2007) denomina capacidad al "conjunto de recursos y aptitudes que tiene un individuo para desempeñar una determinada tarea. El término capacidad también puede hacer referencia a posibilidades positivas de cualquier elemento" (p. 22). En este sentido, esta noción se vincula con la de educación, siendo esta última un proceso de incorporación de nuevas herramientas para desenvolverse en el mundo.

Cuadro 6

Respuestas del Ítem 6 Su aptitud le permite ser un buen docente y un gerente de aula

\begin{tabular}{lll} 
Opciones & Frecuencia & Porcentaje \\
\hline Siempre & 5 & $28 \%$ \\
Casi siempre & 3 & $17 \%$ \\
Algunas veces & 10 & $55 \%$ \\
Casi nunca & - & - \\
Nunca & - & - \\
Total & 18 & $100 \%$ \\
\hline
\end{tabular}

Un 55\% de los docentes encuestados manifiestan que algunas veces su aptitud le permite ser un buen docente y un gerente de aula, seguido de un $28 \%$ que opinaron siempre y un $17 \%$ manifestaron que casi siempre. La actitud es un elemento clave dentro de la profesional docente, especialmente la del nivel de educación inicial, por cuanto se debe manejar no solo con el niño sino con sus padres y representantes ofreciéndole confianza y comodidad para la atención de sus hijos. La palabra aptitud proviene del latín aptitudes 


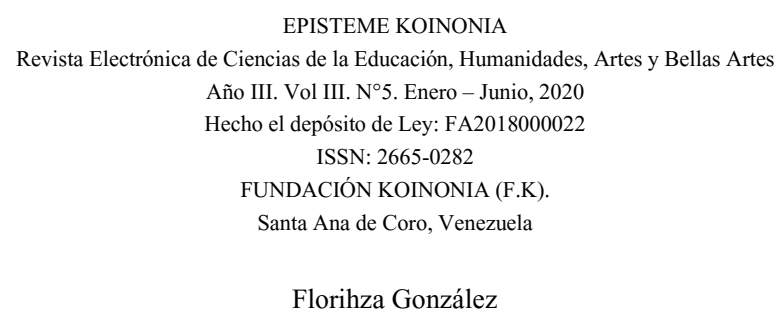

definido por Higuera (2011) como "la capacidad para operar competentemente en una determinada actividad, traduce la disposición para el buen desempeño o ejercicio de la misma, demostrando suficiencia o idoneidad para desempeñarla" (p. 23).

Cuadro 7

Respuestas del Ítem 7 Ha descubierto habilidades docentes que no conocía en usted

\begin{tabular}{lll} 
Opciones & Frecuencia & Porcentaje \\
\hline Siempre & 6 & $33 \%$ \\
Casi siempre & 8 & $45 \%$ \\
Algunas veces & 4 & $22 \%$ \\
Casi nunca & - & \\
Nunca & - & \\
Total & 18 & $100 \%$ \\
\hline
\end{tabular}

Un 45\% opino que casi siempre ha descubierto habilidades docentes que no conocía, seguido de un $33 \%$ con la opción siempre y un $22 \%$ algunas veces. Así como el tiempo de servicio y la experiencia garantizan la adquisición de capacidades, lo mismo ocurre con las habilidades, no es similar las habilidades que tiene un docente con años de servicio en la docencia que uno que apenas se inicia. Caballos (2009) señala que las habilidades personales: "saber escuchar, influir, saber actuar designan aquellas competencias necesarias para actuar en forma eficiente capacidad, inteligencia para ejecutar una cosa la formación de las habilidades depende de las acciones, de los conocimientos y hábitos" (p. 52). 
EPISTEME KOINONIA

Revista Electrónica de Ciencias de la Educación, Humanidades, Artes y Bellas Artes

Año III. Vol III. N ${ }^{\circ}$. Enero - Junio, 2020

Hecho el depósito de Ley: FA2018000022

ISSN: 2665-0282

FUNDACIÓN KOINONIA (F.K)

Santa Ana de Coro, Venezuela

Florihza González

Cuadro 8

Respuestas del Ítem 8 Maneja suficientes destrezas para el trabajo con los niños

\begin{tabular}{|c|c|c|}
\hline Opciones & Frecuencia & Porcentaje \\
\hline Siempre & 4 & $22 \%$ \\
\hline Casi siempre & 1 & $6 \%$ \\
\hline Algunas veces & 13 & $72 \%$ \\
\hline Casi nunca & - & - \\
\hline Nunca & - & - \\
\hline Total & 18 & $100 \%$ \\
\hline
\end{tabular}

El $72 \%$ opina que algunas veces maneja suficientes destrezas para el trabajo con los niños, seguido de un $22 \%$ con la opción siempre, y un $6 \%$ con un casi siempre. Las destrezas del docente de educación inicial son una prioridad por la atención que se brinda a los niños de estas edades. Un docente posee destrezas específicas que le permiten garantizar un proceso pedagógico efectivo, especialmente cuando se hace referencia a los docentes de educación inicial, su vocación es auténtica porque el amor hacia el trabajo con los niños es su esencia, y esta garantiza la efectividad de la gerencia desde su aula.

Cuadro 9

Respuestas del Ítem 9 Es creativo en su trabajo pedagógico

\begin{tabular}{|c|c|c|}
\hline Opciones & Frecuencia & Porcentaje \\
\hline Siempre & 4 & $22 \%$ \\
\hline Casi siempre & 1 & $6 \%$ \\
\hline Algunas veces & 13 & $72 \%$ \\
\hline Casi nunca & - & - \\
\hline Nunca & - & - \\
\hline Total & 18 & $100 \%$ \\
\hline
\end{tabular}




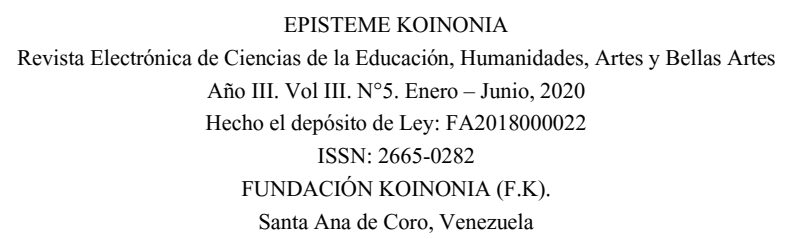

Florihza González

El $72 \%$ de los docentes encuestados considera que algunas veces es creativo en su trabajo pedagógico, seguido de un $22 \%$ que opina con la opción siempre y un $6 \%$ con casi siempre. La creatividad es una condición indispensable para un docente de educación inicial, es su mayor fortaleza, y aunque se considere que es innata se puede desarrollar con el transcurrir del tiempo. Para Monreal (2000) creatividad es: "aquel proceso que produce una obra nueva que es aceptada como defendible o útil o satisfactoria por un grupo en un determinado momento temporal" (p. 56). El docente creativo fomenta el mayor rendimiento de sus estudiantes, y esto depende del grado creativo que le imponga a su práctica pedagógica a través de estrategias innovadoras y novedosas

Cuadro 9

Respuestas del Ítem 9 Es creativo en su trabajo pedagógico

\begin{tabular}{|c|c|c|}
\hline Opciones & Frecuencia & Porcentaje \\
\hline Siempre & 4 & $22 \%$ \\
\hline Casi siempre & 1 & $6 \%$ \\
\hline Algunas veces & 13 & $72 \%$ \\
\hline Casi nunca & - & - \\
\hline Nunca & - & - \\
\hline Total & 18 & $100 \%$ \\
\hline
\end{tabular}

El $72 \%$ de los docentes encuestados considera que algunas veces es creativo en su trabajo pedagógico, seguido de un $22 \%$ que opina con la opción siempre y un $6 \%$ con casi siempre. La creatividad es una condición indispensable para un docente de educación inicial, es su mayor fortaleza, y aunque se considere que es innata se puede desarrollar con el transcurrir del tiempo. Para Monreal (2000) creatividad es: "aquel proceso que produce una obra nueva que es aceptada como defendible o útil o satisfactoria por un grupo en un determinado momento temporal" (p. 56). El docente 


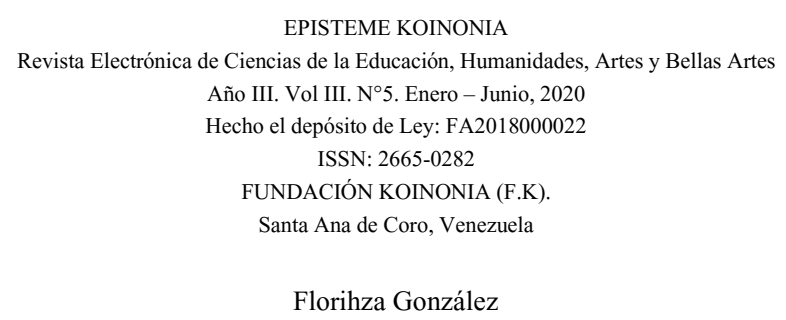

creativo fomenta el mayor rendimiento de sus estudiantes, y esto depende del grado creativo que le imponga a su práctica pedagógica a través de estrategias innovadoras y novedosas.

Cuadro 10

Respuestas del Ítem 10 Es usted gerente en su aula

\begin{tabular}{lll} 
Opciones & Frecuencia & Porcentaje \\
\hline Siempre & 5 & $28 \%$ \\
Casi siempre & 13 & $72 \%$ \\
Algunas veces & - & - \\
Casi nunca & - & - \\
Nunca & - & - \\
Total & 18 & $100 \%$ \\
\hline
\end{tabular}

La mayoría de los docentes encuestados manifiesta en un $72 \%$ que casi siempre son gerentes en su aula, mientras que una minoría representada por el $28 \%$ siempre lo es. Cada docente preserva una autonomía desde su micro espacio de aprendizaje, siguiendo las directrices y lineamientos inmediatos por parte de la Dirección, sin embargo tiene un alto grado la acción gerencial que se cumpla desde el aula, como un rasgo de autonomía en su desempeño pedagógico. Ruiz (1992) considera que "la gerencia de aula se refiere a la previsión y procedimientos necesarios para establecer y mantener un ambiente en el cual la instrucción y el aprendizaje puedan suceder" (p. 8). El aula es una organización socio educativa que requiere de condiciones para que se produzca el conocimiento a través del diseño y ejecución de estrategias y recursos para fomentar una preparación acorde a las exigencias sociales. 
EPISTEME KOINONIA

Revista Electrónica de Ciencias de la Educación, Humanidades, Artes y Bellas Artes

Año III. Vol III. N ${ }^{\circ}$. Enero - Junio, 2020

Hecho el depósito de Ley: FA2018000022

ISSN: 2665-0282

FUNDACIÓN KOINONIA (F.K)

Santa Ana de Coro, Venezuela

Florihza González

Cuadro 11

Respuestas del Ítem 11 Es proactivo

\begin{tabular}{lll} 
Opciones & Frecuencia & Porcentaje \\
\hline Siempre & 5 & $28 \%$ \\
Casi siempre & 2 & $11 \%$ \\
Algunas veces & 11 & $61 \%$ \\
Casi nunca & - & - \\
Nunca & - & - \\
Total & 18 & $100 \%$
\end{tabular}

El $61 \%$ de los docentes encuestados considera que algunas veces es proactivo, seguido de un $28 \%$ que considera que siempre lo es y un $11 \%$ casi siempre. Ser un docente proactivo tiene relación con la actitud y la vocación con la cual se lleve a cabo el desempeño pedagógico, es saber estar preparado a las demandas y exigencias de los niños de educación inicial. Según Guerrero Serón (1993), la proactividad del gerente es saber hacerle frente a las adversidades y dificultades que se anticipen, implica estar preparado para dar respuesta oportuna a los acontecimientos que estén cargados de incertidumbre. Es una actitud de preparación para ser efectivo ante las situaciones de desacierto.

Cuadro 12

Respuestas del Ítem 12 Asume las criticas propias y ajenas acerca de su accionar pedagógico

\begin{tabular}{lll} 
Opciones & Frecuencia & Porcentaje \\
\hline Siempre & 5 & $28 \%$ \\
Casi siempre & 2 & $11 \%$ \\
Algunas veces & 11 & $61 \%$ \\
Casi nunca & - & - \\
Nunca & - & - \\
Total & 18 & $100 \%$ \\
\hline
\end{tabular}




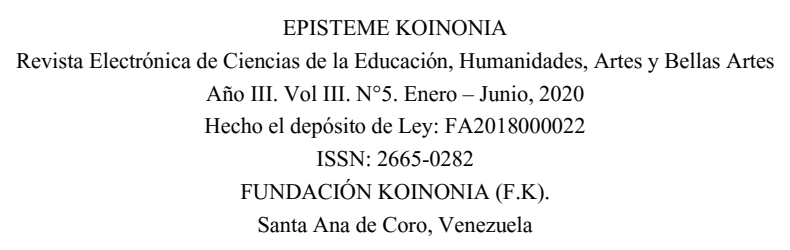

Florihza González

El $61 \%$ de los docentes encuestados asume las criticas propias y ajenas acerca de su accionar pedagógico, seguido de un $28 \%$ con la opción siempre y un $11 \%$ casi siempre. El docente debe estar abierto y receptivo hacia sus propias críticas y las de otros sobre su accionar pedagógico, es decir, aceptar las críticas constructivas para el mejoramiento de su desempeño docente. Según Guerrero Serón (1993) el espíritu crítico es aquel que le permite respetar sus ideales y principios bajo los cuales dirige al grupo u organización, permitiendo seleccionar la información relevante de la irrelevante y en función a ella tomar decisiones de forma asertiva para la empresa.

\section{Cuadro 13}

Respuestas del Ítem 13 Reflexiona sobre su práctica pedagógica

\begin{tabular}{lll} 
Opciones & Frecuencia & Porcentaje \\
\hline Siempre & 5 & $25 \%$ \\
Casi siempre & 3 & $15 \%$ \\
Algunas veces & 12 & $60 \%$ \\
Casi nunca & - & \\
Nunca & - & \\
Total & 18 & $100 \%$ \\
\hline
\end{tabular}

El $60 \%$ de los docentes encuestados reflexiona algunas veces su práctica pedagógica, seguido de un $25 \%$ que siempre lo hace y un $15 \%$ casi siempre. La reflexión como parte del trabajo docente es fundamental considerando que se debe accionar para mejorar aquellas debilidades que se tengan como docentes. Según Guerrero Serón (1993) tomar decisiones implica reflexionar sobre el deber ser y asumir equivocaciones con la suficiente madurez para reparar y reflexionar en virtud de mejorar las debilidades. 


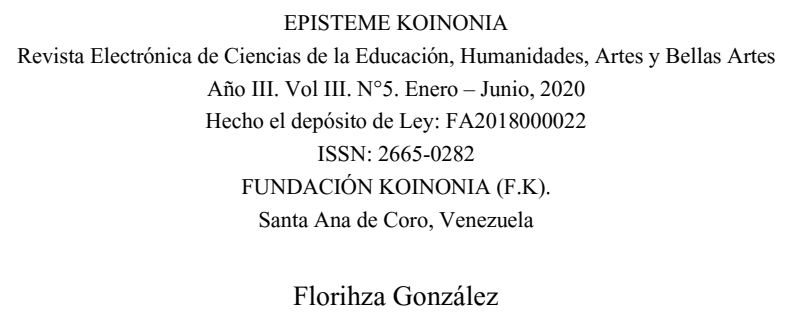

\section{CONCLUSIONES}

Luego de aplicar el cuestionario como instrumento de recolección de datos a los docentes del CEIB Lucrecia de Guardia, su posterior análisis estadístico descriptivo, y en concordancia con los objetivos específicos establecidos para la investigación, se concluye:

Con respecto al primer objetivo específico relacionado con los aspectos que definen la vocación del colectivo docente en el CEIB Lucrecia de Guardia, de acuerdo a los resultados las maestras de esta institución poseen una vocación de tipo subjetiva caracterizada por atracción a su profesión pero son pocas las que tienen las cualidades para ello. Sin embargo, el personal es responsable y ético en su trabajo, las exigencias y lineamientos curriculares son cumplidas. A pesar de existir una minoría de docentes con vocación autentica, es decir, tienen la afinidad y las cualidades para ser docentes de educación inicial, el compromiso asumido para el trabajo pedagógico con los niños se cumple por el resto del grupo.

Es por ello, que los aspectos que definen la vocación del docente de educación inicial van enfocados hacia la capacidad de trabajar en equipo, responsabilidad, tareas manuales, salud física y mental, buen trato entre colegas, tolerancia, paciencia, firmeza, cualidades morales; elementos que se evidencian en cada uno de los docentes que conforma dicho colectivo. El compromiso y la responsabilidad juegan un papel importante en los años de servicio ejerciendo la docencia, más colectivo que individual pero implica una cohesión social que permite como organización educativa social tener una proyección positiva ante la comunidad.

Cada docente se diferencia uno del otro, sin embargo al consolidarse como grupo de trabajo se enfoca hacia el logro de objetivos institucionales. La vocación se mide por el entusiasmo, la vitalidad, afectividad y efectividad del docente en realizar sus acciones. El ser docente de vocación implica reforzar sus aspectos personales carismáticos hacia el trabajo pedagógico. Sus funciones no solo es el de transmitir información ni facilitar el aprendizaje, es además, crear un ambiente de aprendizaje enriquecido, donde se 


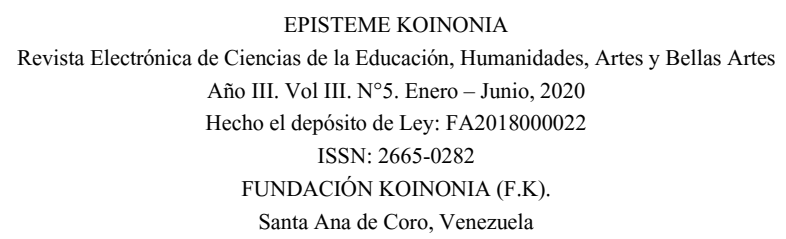

Florihza González

aprenda a través de acciones constructivas, ser mediador en lo que el niño exige en aprender. Para que el docente le agregue entusiasmo a su desempeño pedagógico debe reflexionar y evaluar su práctica educativa con los niños, mejorando sus debilidades.

Seguidamente, el segundo objetivo específico vinculado a las acciones para el enriquecimiento de la vocación docente desde su práctica pedagógica, estas implican la formación de un docente autónomo y reflexivo, que lleve a cabo procesos de enseñanza y aprendizaje por una simple aplicación del currículo, sino además que reflexione sobre su práctica. Debe enfocarse hacia una pedagogía dinámica, estratégica, autorregulada y reflexiva. Además su quehacer cotidiano debe ser objeto de reflexión y sistematización para utilizar las herramientas que le permitan asumir roles de orientador, investigador, planificador, evaluador, entre otras.

Del mismo modo, debe preocuparse por convertir cada espacio físico de la institución en un lugar enriquecido y significativo para el aprendizaje, dejar la rutina y la monotonía, buscar siempre la innovación y transformación, trabajar en la construcción y reconstrucción de la práctica educativa de forma individual y colectiva. El docente enriquece su vocación a través de acciones como saber comunicarse, oír activamente, respetar las posturas de los demás, valorar las diferencias, despertar la curiosidad por el conocimiento de acuerdo a las etapas de desarrollo de cada niño, darle respuesta a los retos, hacer uso de los diferentes medios y tecnologías de información y comunicación, fomentar el crecimiento personal, la autoestima y el liderazgo.

Por último, el tercer objetivo específico relacionado con los elementos de la vocación docente necesarios para su rol como gerente de aula, se amerita no solo ser mediador de experiencias y conocimientos significativos sino además tener efectividad para gerenciar tiempo, conflicto, comunicación, toma de decisiones, ambientes físicos, motivación, innovación. Solo el docente con vocación autentica es capaz de llevar a cabo una planificación y todas las actividades allí diseñadas, además de tomar en cuenta las fortalezas y debilidades en su ámbito de acción, que es el aula de clases, unidas con el currículo y desarrollar un proceso enriquecedor de aprendizaje, enseñanza, experiencias 


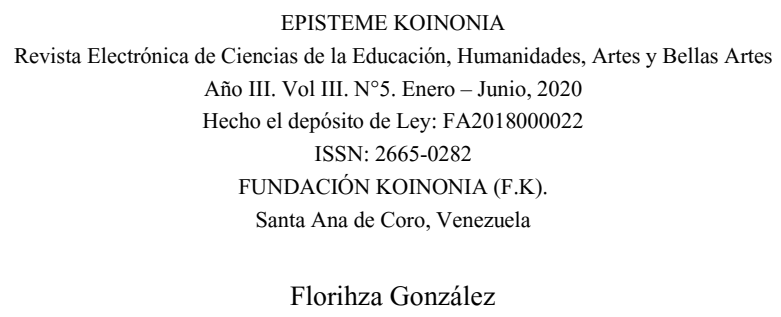

y conocimientos. Asimismo, no solo es el cumplimiento de las funciones administrativas sino además aquellas acciones que fortalezcan su crecimiento personal, ético, espíritu y creativo propio y de cada niño a su cargo.

Desde esta perspectiva, se puede sumar a estos aspectos su acción transformadora en la sociedad, impulsando sus funciones de guía, orientador, investigador, participativos, facilitador, motivador y creador de oportunidades fascinantes de enseñanza aprendizaje utilizando técnicas y estrategias que satisfagan las inquietudes de los niños. Debe prepararse y actualizar su pedagogía, adquiriendo conocimientos nuevos para implementar desde su aula, tener una actitud proactiva, critica y reflexiva frente a enseñanza buscando su excelencia como valor social, ser exigente consigo mismo para ser mejor cada día.

FINANCIAMIENTO: No monetario

AGRADECIMIENTOS: Un especial agradecimiento a los docentes de CEIB Lucrecia de Guardia, ubicada en Coro, municipio Miranda del Estado Falcón por el apoyo brindado para la realización de esta investigación.

\section{REFERENCIAS}

Arias, F. (2009). El Proyecto de Investigación. Guía para su elaboración. [The Research Project. Guide for its elaboration] Caracas: Epísteme. Quinta Edición.

Borrero, R. (2019). Procesos de gestión del talento humano en el sector educativo gerencial de Colombia. [Human talent management processes in the managerial educational sector of Colombia.] Revista Arbitrada Interdisciplinaria Koinonía, 4(7), 293-307. doi: http://dx.doi.org/10.35381/r.k.v4i7.206

Caballos, V. (2009) Manual de evaluación y entretenimiento de las habilidades sociales. [Social skills assessment and entertainment manual] .Siglo Veintiuno. Madrid.

Dubet, F.; Duru y Bellat, M. (2000). La crisis escolar: por un colegio democrático. [The school crisis: for a democratic school]. Paris: Seuil. 


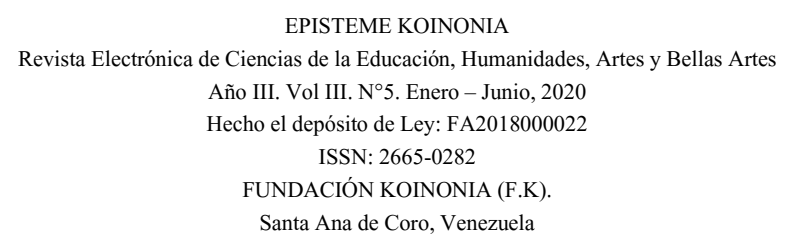

Florihza González

Guerrero Serón, A. (1993): Maestras y maestros. Autonomía, práctica docente y sindicación en una profesión subordinada. Un estudio sociológico. [Teachers and teachers. Autonomy, teaching practice and unionization in a subordinate profession. A sociological study]. Madrid: Ed. Universidad Complutense de Madrid

Higuera, R. (2011) Desarrollo de las Competencias Afectivas. [Development of Affective Competences]. Editorial: Libros Impresos

Hernández, A. (2018). Transitando por el camino de la escuela para padres, madres y representantes. Una experiencia vivida. [Walking on the way to school for parents and representatives. A lived experience]. EPISTEME KOINONIA, 1(1), 51-71. Recuperado de https://n9.cl/tnnnl

Jiménez, D. (2007). La orientación como herramienta de progreso. [Orientation as a tool for progress]. Barquisimeto-Edo-Lara

Lapati, P. (2003). ¿Cómo aprenden los maestros? Conferencia magistral en el XXXV aniversario de la Escuela Normal Superior del Estado de México. [How do teachers learn? Master conference on the XXXV anniversary of the Superior Normal School of the State of Mexico]. Toluca, 18 de enero de 2003. Cuadernos de Discusión 6.

Méndez, M. (2004). Gerencia de aula en el proceso enseñanza aprendizaje en la asignatura sistemas operativos en el área de aduanas. [Classroom management in the teachinglearning process in the subject operating systems in the customs area] Trabajo de Grado no Publicado. Universidad de Carabobo, Valencia.

Monreal, C. (2000). Qué es la creatividad. [What is creativity] Madrid: Biblioteca Nueva

Romero, M., \& Villasmil, J. (2017). Repensar la formación docente. Hacia el encuentro de una nueva perspectiva epistémica para su abordaje y resignificación. [Rethink teacher training. Towards the meeting of a new epistemic perspective for its approach and resignification]. CIENCIAMATRIA, 3(5), 133-149. https://doi.org/10.35381/cm.v3i5.17

Robbins, S. (1999) Comportamiento Organizacional. México. D.F; Pearson Education.

Ruíz, L. (1992). Gerencia en el aula. [Management in the classroom]. Venezuela: FEDUPEL.

Salazar, J. (1994). Gerencia de Aula. [Classroom Management]. Trabajo de grado entregado para publicación. (UPEL). Venezuela: Lara.

Sánchez, E. (2003). La vocación entre los aspirantes a maestros. [The vocation among aspiring teachers]. Educación XX. 